\title{
Identification of functional CCAAT/enhancer-binding protein and Ets protein binding sites in the human chorionic somatomammotropin enhancer sequences
}

\author{
Aristides Lytras, Karen Detillieux and Peter A Cattini \\ Department of Physiology, University of Manitoba, Room 444, 745 Bannatyne Avenue, Winnipeg, Manitoba, Canada R3E 0J9 \\ (Correspondence should be addressed to A Lytras; Email: aristides.lytras@joslin.harvard.edu; peter_cattini@umanitoba.ca)
}

\begin{abstract}
The human chorionic somatomammotropin (CS) A and B genes (listed as $\mathrm{CSH} 1$ and $\mathrm{CSH} 2$ in the HUGO database) are highly expressed in placenta. A 241 bp potent enhancer, nucleotides (nts) 1-241, located at the $3^{\prime}$ end of the CS-B gene (CS-Benh) stimulates promoter activity specifically in placental trophoblast cells in vitro. Strong activity is exerted by a 23 bp element within the CS-Benh (nts 117-139), shown to interact with transcription enhancer factor (TEF) members of the transcription enhancer activator (TEA) DNA-binding domain-containing family. An identical TEF element is present in the homologous (97.5\%) CS-Aenh; however, a few nucleotide differences suppress its activity. Previously, we identified regulatory sequences distinct from the TEF element within an $80 \mathrm{bp}$ modulatory domain (nts 1-80) in the CS-Benh. Using structural and functional assays we now show that CCAAT/enhancer-binding protein (C/EBP) binding sites exist in the $80 \mathrm{bp}$ modulatory domains of both enhancers, and an Elk-1 binding site exists in the modulatory domain of the CS-Aenh. $\mathrm{C} / \mathrm{EBP} \alpha$ or $\mathrm{C} / \mathrm{EBP} \beta$ strongly repressed CSp.CAT activity but stimulated CSp.CAT.CS-Benh activity. In contrast, the equivalent $C S-A$ enhancer sequences were unable to relieve promoter repression. Elk-1 overexpression also resulted in differential effects on the CS-Aenh versus CS-Benh. Finally, we provide evidence for the association of C/EBP $\beta$ with the $C S-A$ and $C S-B$ genes in human placental chromatin, including differential involvement of C/EBP $\beta$ with the CS-Aenh versus the CS-Benh, and therefore consistent with the notion that these are regions of regulatory significance in vivo. We conclude that members of the C/EBP and Ets families can differentially modulate CS-Benh and CS-Aenh activity.
\end{abstract}

Journal of Molecular Endocrinology (2011) 47, 179-193

\section{Introduction}

The human chorionic somatomammotropin (CS) genes ( $C S-A$ or $C S H 1$ and $C S-B$ or $C S H 2$ ) are expressed at very high levels in placenta throughout pregnancy. The sequence requirements for efficient in vivo CS expression have not as yet been determined (Kimura et al. 2007, Jin et al. 2009). However, a 241 bp region, nucleotides (nts) 1-241, located about $2 \mathrm{~kb}$ downstream of the $C S-B$ gene has been identified, and shown to enhance homologous or heterologous promoter activity by up to 300 - to 400 -fold specifically in placental trophoblasts cells in vitro (Walker et al. 1990, Jacquemin et al. 1994, Jiang \& Eberhardt 1994, Lytras \& Cattini 1994). In addition, the 'enhancer' region was shown to contain hyperacetylated histone $\mathrm{H} 3$ and $\mathrm{H} 4$ in primary human placental and choriocarcinoma (BeWo) cells in culture (Kimura et al. 2007). A family of transcription factors has been identified containing an evolutionarily conserved binding domain that is referred to as the TEA (TEF-1, Tec1p, and AbaAp) or ATTS (AbaAp, TEF-1, Tec1p, and Scalloped) motif. The transcription enhancer factors (TEFs) are members, and have been shown to interact with sequences in the $C S-B$ enhancer.
Specifically, TEF-1, the first member of this family (Xiao et al. 1991), was highlighted as the major factor (Walker et al. 1990, Jacquemin et al. 1994, Jiang \& Eberhardt 1994, Lytras \& Cattini 1994). This was supported by its binding to the minimal $23 \mathrm{bp}$ (nts 117-139) CS-B enhancer element (Fig. 1) as well as to flanking sequences (Walker et al. 1990, Jacquemin et al. 1996, Jiang et al. 1997, 2000). Subsequently TEF-5, which is relatively more abundant in the placenta, was suggested to mediate CS enhancer activity (Jacquemin et al. 1997, Jiang et al. 1999). Furthermore, TEF-1 overexpression in several cell types repressed transcriptional activity (Xiao et al. 1991, Jiang \& Eberhardt 1995, 1996).

It is already apparent that additional transcription elements/factors bind to elements in the enhancer region and modify the activity of TEFs (Jiang \& Eberhardt 1995, 1996, Jiang et al. 1997). At the DNA level, this notion is supported by the observation that the minimal $23 \mathrm{bp} C S-B$ TEF enhancer element is not as potent as the $241 \mathrm{bp} C S-B$ enhancer fragment (Walker et al. 1990, Jacquemin et al. 1994, Jiang \& Eberhardt 1994, Lytras \& Cattini 1994). We provided evidence for both repressor (RF-1) and derepressor (DF-1) elements within an $80 \mathrm{bp}$ modulatory domain (nts 1-80, Fig. 1)

DOI: 10.1530/JME-11-0025 Online version via http://www.endocrinology-journals.org 


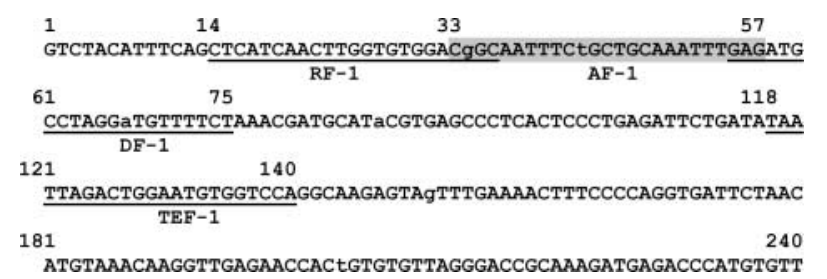

Figure 1 The nucleotide sequence of the human $C S-B$ enhancer region. The positions of previously identified TEF-1 (Walker et al. 1990), RF-1 and DF-1 (Lytras \& Cattini 1994), and AF-1 (Lytras et al. 1996) regions are indicated by underlining or shading. Differences between the $C S-B$ and $C S-A$ enhancers are indicated by lower case characters.

adjacent to the minimal enhancer region in the $241 \mathrm{bp}$ $C S-B$ enhancer fragment (Lytras \& Cattini 1994). An auxiliary region (AF-1, Fig. 1) was also identified that on mutation eliminated $C S-B$ enhancer activity (Lytras et al. 1996). A comparison of CS-A and CS-B 'enhancer' regions also provides evidence for additional regulatory elements/factors. The $241 \mathrm{bp}$ $C S-A$ 'enhancer' region failed to stimulate promoter activity in an efficient manner, even though it contains the identical minimal $23 \mathrm{bp}$ enhancer element and high affinity TEF binding site as found in equivalent CS-B sequences (Rogers et al. 1986, Jacquemin et al. 1996, Lytras et al. 1996). The difference in activity between the $C S-A$ and $C S-B$ 'enhancer' regions was traced to one and two nucleotide differences in the DF-1 and AF-1 regions, respectively, which lie outside the minimal 23 bp TEF enhancer element (Fig. 1; Rogers et al. 1986, Lytras \& Cattini 1994, Lytras et al. 1996).

With regard to the mechanism of $C S-B$ enhancer action, it has been suggested that the AF-1 and DF-1 regions of $C S-B$ (i.e. AF- $1 \mathrm{~B}$ and $\mathrm{DF}-1 \mathrm{~B}$, respectively) contain lower affinity TEF sites that act in combination with additional TEF sites present in the $C S-B$ enhancer (Fig. 1; Jiang \& Eberhardt 1994, Jiang et al. 1997). In this study, we examined the alternative possibility that members of other transcription factor families participate in complexes formed on the AF- 1 region of $C S-A$ (AF-1A) and/or AF-1B sequences. Our data demonstrate binding by members of the CCAAT/enhancer-binding protein $(\mathrm{C} / \mathrm{EBP})$ and Ets families of transcription factors. In addition, we show that these factors are capable of modifying relative $C S$ promoter activity under the influence of the $C S-A$ versus $C S-B$ enhancers. Furthermore, we provide evidence that factors interacting directly or indirectly with the minimal TEF enhancer element can also interact with the AF-1A or AF-1B regions. Finally, we provide evidence that $\mathrm{C} / \mathrm{EBP} \beta$ associates with $C S-A$ and $C S-B$ sequences in human term placental chromatin in situ, including differential interaction of $\mathrm{C} / \mathrm{EBP} \beta$ with the CS-Aenh versus the CS-Benh. These results support the notion that factors other than TEFs, specifically members of the $\mathrm{C} / \mathrm{EBP}$ and
Ets families, can differentially modulate $C S-A$ and $C S-B$ enhancer activities, and that these enhancer regions are of regulatory significance in vivo.

\section{Materials and methods}

\section{Materials}

Chemicals and reagents were obtained from Sigma, St Louis, MO, USA; GIBCO-BRL, Burlington, ON, Canada; ICN/FLOW, Cleveland, OH, USA; Pharmacia, Baie d'Urfé, QC, Canada; Mallickrodt, Paris, KY, USA; Fisher Fair Lawn, Fair Lawn, NJ, USA; Bio-Rad, Missisauga, ON, Canada; Aldrich Chem. Comp., Inc., Milwaukee, WI, USA and DuPONT, Boston, MA, USA. Monoclonal antiFLAG antibodies (M2) were from Sigma, anti-FGF receptor monoclonal antibodies (anti-FGFR) from QED Bioscience, Inc. (San Diego, CA, USA) and antihuman retinoblastoma monoclonal antibodies (anti$\mathrm{Rb}$ ) from Pharmingen (San Diego, CA, USA).

\section{Plasmid construction}

A $1022 \mathrm{bp}$ fragment of the CS-B gene containing placental enhancer sequences was provided by Dr G F Saunders (M.D. Anderson Cancer Center, Houston, TX, USA). A $241 \mathrm{bp} \mathrm{AccI/PvuII} \mathrm{fragment} \mathrm{containing}$ the $22 \mathrm{bp}$ TEF enhancer element was isolated from the $1022 \mathrm{bp}$ fragment and subcloned into PUC19 as described previously (Lytras \& Cattini 1994). The isolation of $C S-A$ and $C S-B 265$ bp enhancer regions from genomic DNA by PCR and their subcloning to PUC119 vectors has been previously described (Lytras et al. 1996).

A PUC19 vector that contained the $241 \mathrm{bp} C S-B$ enhancer fragment (Lytras \& Cattini 1994) was digested with HindIII and BamHI. A $2 \cdot 2 \mathrm{~kb}$ fragment containing the CS promoter $(C S p)$ fused immediately upstream of the chloramphenicol acetyl transferase (CAT) gene was excised after HindIII/BamHI digestion from a vector containing CSp.CAT as described previously (Lytras \& Cattini 1994) and ligated to HindIII and BamHI digested $C S-B$ enhancer-containing PUC19, placing the $C S-B$ enhancer downstream of the $C A T$ gene. To generate a similar $C S-A$ enhancer construct, a PUC119 vector containing a 265 bp CS-A enhancer fragment was digested by HindIII/BamHI and the HindIII/BamHI $2 \cdot 2 \mathrm{~kb}$ CSp.CAT fragment was inserted upstream of the $C S$-A enhancer.

A hybrid $C A T$ gene $S V 40 p 35$ containing the $22 \mathrm{bp}$ high affinity TEF site inserted directionally at the BamHI/SalI sites downstream of the CAT gene directed by the SV40 promoter (pCAT-Basic Vector; Promega) has been described (Nachtigal et al. 1993). For hybrid CAT genes containing AF-1 oligonucleotides, a $25 \mathrm{bp}$ 
AF-1A or AF-1B oligonucleotide (nts 33-57) was inserted in the forward orientation at the BamHI site immediately upstream of the TEF element maintaining the $5^{\prime}-3^{\prime}$ positioning of the two elements within the 241 bp enhancer fragment.

Expression vectors for: Elk-1 (with C-terminus FLAG) was provided by Dr Sharrocks; for pCMV-Elf-R and pCMV-Elf-1 were provided by $\mathrm{Dr}$ Kovar; RcCMV-C/EBP $\alpha$ (N-terminus FLAG-tagged), RcCMV$\mathrm{C} / \mathrm{EBP} \beta$ (N-terminus FLAG-tagged), CMV-C/EBP $\alpha$, and CMV-C/EBP $\beta$ were provided by $\mathrm{Dr}$ Schaufele; and pcDNA3/ets-1 and pcDNA3/ets-2 were provided by Dr Papas.

\section{Cell culture and DNA transfer}

Human choriocarcinoma JEG-3 cells were obtained from the American Type Culture Collection (ATCC), Manassas, VA, USA and grown in monolayer in DMEM supplemented with $8-10 \%$ fetal bovine serum in a humidified atmosphere of $95 \%$ air and $5 \% \mathrm{CO}_{2}$. Cells were grown on 60-100 $\mathrm{mm}$ culture dishes and harvested when they reached about $80 \%$ confluence. For plasmid DNA transfer, JEG-3 cells were plated in $60-100 \mathrm{~mm}$ culture dishes at a density of $1-2 \times 10^{6}(20-40 \%$ confluence) and transiently transfected by calcium phosphate-DNA precipitation after $20-26 \mathrm{~h}$ as described (Cattini \& Eberhardt 1987). Each plate was transfected with an individual DNA precipitation, unless otherwise stated. The culture medium containing the DNA precipitate was replaced by fresh medium 20-24 h later and cells were harvested 22-24 $\mathrm{h}$ after the addition of the fresh medium. Pellets were resuspended in $0 \cdot 1 \%$ v/v Triton X-100/100 mM Tris- $\mathrm{HCl} \mathrm{pH} 7 \cdot 8$, transferred to $1.5 \mathrm{ml}$ microfuge tubes and incubated for $20 \mathrm{~min}$ on ice. After centrifugation for $15 \mathrm{~min}$ at $4{ }^{\circ} \mathrm{C}$ the supernatant (cell extracts) was assayed for luciferase and/or CAT activity or placed at $-70{ }^{\circ} \mathrm{C}$ until assayed. Protein concentrations were determined by the Bradford microassay (Bradford 1976) with BSA as a standard, by measuring absorption at $595 \mathrm{~nm}$ (A595). CAT activity was measured using a modification of the two-phase fluor diffusion assay as described previously (Nickel et al. 1990). Quantitative values for CAT activity were determined by regression analysis and were corrected for the amount of protein per sample (c.p.m./mg of cell extract protein). CAT activity was also expressed as fold increase over the basal SV40 or CSp activity. Correction for transfection efficiency and DNA uptake was obtained by co-transfection with a CMV-1/luciferase gene hybrid construct $(0 \cdot 2-1 \cdot 0 \mu \mathrm{g} /$ plate $)$ and assessment of the luciferase activity of the cell extracts. For transcription factor overexpression experiments, $5 \mu \mathrm{g}$ of each expression vector or control vector were used. For these experiments luciferase correction was only done for determining the fold induction over basal promoter activity only when the same vector(s) were used for the $C S p$ and CSpCSenh constructs as different transcription factors had differential effects on CMV promoter activity (A Lytras \& PA Cattini, unpublished observations).

\section{Preparation of nuclear extracts}

Nuclear extracts were prepared from cells transfected with expression vectors carrying cDNAs for transcription factors or control vectors as described previously (Andrews \& Faller 1991). Extracts in buffer C $(20 \mathrm{mM}$ HEPES-KOH pH 7.9, 25\% glycerol, $0 \cdot 42 \mathrm{NaCl}, 1 \cdot 5 \mathrm{mM}$ $\mathrm{MgCl}_{2}, 0.2 \mathrm{mM}$ EDTA, $0.5 \mathrm{mM}$ dithiothreitol (DTT), $1 \mathrm{mM}$ phenylmethylsulfonyl fluoride) were stored at $-70^{\circ} \mathrm{C}$. Protein concentrations were determined as above.

\section{Electrophoretic mobility shift assays}

For electrophoretic mobility shift assays (EMSAs), JEG-3 extracts (2.5-12 $\mu \mathrm{g})$ in 6-13 $\mu \mathrm{l}$ buffer C (see above) were incubated with ${ }^{32} \mathrm{P}$-end-labeled DNA fragments or synthetic oligonucleotides $\left(0 \cdot 2-2 \cdot 0 \mathrm{ng} ; 2-5 \times 10^{4}\right.$ c.p.m. diluted in 4-6 $\mu$ l buffer D (10 mM HEPES-NaOH $\mathrm{pH}$ $7 \cdot 9,50 \mathrm{mM} \mathrm{KCl}, 0.5 \mathrm{mM}$ EDTA, $10 \%$ glycerol, $1 \mathrm{mM}$ DTT)) in the presence of $2 \mu \mathrm{g}$ of poly dI-dC in a final volume of 15-18 $\mu$ l. Incubation of the reaction on ice for $20 \mathrm{~min}$ and at room temperature for $15 \mathrm{~min}$ was followed by electrophoresis in non-denaturing $4 \%$ polyacrylamide gels with 1:60 bis to acrylamide cross-linking ratio. For competition, 10-250 ng double-stranded synthetic oligonucleotides were added to nuclear extracts on ice before the addition of the radiolabeled DNA. For 'supershift' experiments, 3.5-6 $\mu \mathrm{g}$ of nuclear extracts (in $10-10 \cdot 5 \mu \mathrm{l}$ buffer $\mathrm{C}$ ) were incubated on ice with $2 \mu \mathrm{g}$ of M2 anti-FLAG antibody or, as controls, $2 \mu \mathrm{g}$ anti-FGFR 1 or $2 \mu \mathrm{g}$ anti-Rb, monoclonal antibodies for $40 \mathrm{~min}$. Subsequently, radiolabeled double-stranded AF-1A or AF-1B oligonucleotides $\left(\sim 1 \mathrm{ng}, 40-50 \times 10^{3}\right.$ c.p.m.) and $2 \mu \mathrm{g}$ of poly dI-dC in buffer $\mathrm{D}$ were added per sample to a final volume of 15-16 $\mu$ l, incubated on ice for $45 \mathrm{~min}$ and at room temperature for $15 \mathrm{~min}$ before loading on non-denaturing $5 \%$ polyacrylamide gels ( $1: 60$ bis to acrylamide cross-linking ratio). For autoradiography Kodak XAR films were exposed for $18 \mathrm{~h}$ to 10 days at $-70^{\circ} \mathrm{C}$ in a cassette with intensifying screens (DuPONT).

\section{ChIP on chip tiling array assays}

'ChIP on chip' tiling array assays were performed by Active Motif (Carlsbad, CA, USA). Human term placenta tissue was fixed with $1 \%$ formaldehyde for $15 \mathrm{~min}$ and quenched with $0 \cdot 125 \mathrm{M}$ glycine. Collection of term placental tissue was carried out under the 
approval of the Bannatyne Campus Research Ethics Board of the University of Manitoba. Term placentas were collected from routine births at the Women's Hospital (Winnipeg, MB, Canada) as discarded tissue with no connection to the identity or family history of mother or newborn. Chromatin was isolated by adding lysis buffer, followed by disruption with a motorized pestle. Lysates were sonicated and the DNA sheared to an average length of 300-500 bp. Genomic DNA (Input) was prepared by treating aliquots of chromatin with RNase, proteinase $\mathrm{K}$ and heat for de-crosslinking, followed by ethanol precipitation. Pellets were resuspended and the resulting DNA was quantified on a NanoDrop spectrophotometer. Extrapolation to the original chromatin volume allowed quantitation of the total chromatin yield.

An aliquot of chromatin $(20-30 \mu \mathrm{g})$ was precleared with protein A or $\mathrm{G}$ agarose beads (Invitrogen). Genomic DNA regions of interest were isolated using an antibody against C/EBP $\beta$ (Santa Cruz Biotechnology, Inc., Santa Cruz, CA, USA). After incubation at $4{ }^{\circ} \mathrm{C}$ overnight, protein $\mathrm{A}$ or $\mathrm{G}$ agarose beads were used to isolate the immune complexes. Complexes were washed, eluted from the beads with SDS buffer, and subjected to RNase and proteinase $\mathrm{K}$ treatment. Cross-links were reversed by incubation overnight at $65^{\circ} \mathrm{C}$, and ChIP DNA was purified by phenol-chloroform extraction and ethanol precipitation.

ChIP DNA was amplified by whole genome amplification (WGA) using the GenomePlex WGA Kit (Sigma). The amplified DNA was fragmented and labeled using the DNA Terminal Labeling Kit from Affymetrix (Santa Clara, CA, USA), and then hybridized to Affymetrix GeneChip Tiling arrays at $45^{\circ} \mathrm{C}$ overnight. Arrays were washed and scanned, and the resulting CEL files were analyzed using Affymetrix TAS software. Thresholds were selected, and the resulting BED files were analyzed using Genpathway software (proprietary) that provides comprehensive information on genomic annotation, peak metrics and sample comparisons for all peaks (intervals). To verify peaks, the results for ChIP DNA were normalized against existing input DNA array data (Active Motif database) from three different human genomes.

\section{Statistical analysis}

Unpaired $t$-tests and (ANOVA) or nonparametric ANOVA (Kruskal-Wallis) were used to assess the statistical significance of differences observed in these studies. When the results of the ANOVA indicated the presence of a significant difference, a Bonferroni post hoc test or Dunn's Multiple Comparisons Test was applied (InStat). Significance was defined by $P<0 \cdot 05$.

\section{Results}

\section{The AF-1A region interferes with TEF enhancer activity on a heterologous SV40 promoter}

Previously, we had observed a $65 \%$ decrease in the activity of the minimal TEF enhancer element in the presence of the AF-1 region from the $C S-B$ gene (AF-1B) in the context of a SV40 promoter-directed CAT reporter gene (Lytras et al. 1996). We have now expanded this experiment to include the analogous region from $C S-A$ (AF-1A) by comparing the activities of the SVp.CAT.AF-1B.TEF and SVp.CAT.AF-1A.TEF constructs, relative to the basic SVp.CAT and SVp.CAT.TEF (Fig. 2). The activity observed with SVp.CAT.AF-1A.TEF was comparable to that of the enhancerless SVp.CAT construct (Fig. 2). Thus, while AF-1B showed significant repression of TEF-induced activity $(n=23-30, P<0 \cdot 05)$, AF-1A completely abolished it $(n=6-23, P<0 \cdot 001)$.

\section{The AF-1A and AF-1B regions show different EMSA patterns, and TEF oligonucleotides compete with varying affinities for some AF-1A and AF-1B complexes}

Nuclear extracts from placental choriocarcinoma (JEG-3) cells were used to compare the EMSA patterns obtained with the AF-1A and AF-1B regions. Multiple complexes of various mobilities were observed with both regions (C1, C2, and C3; Fig. 3). In addition, multiple

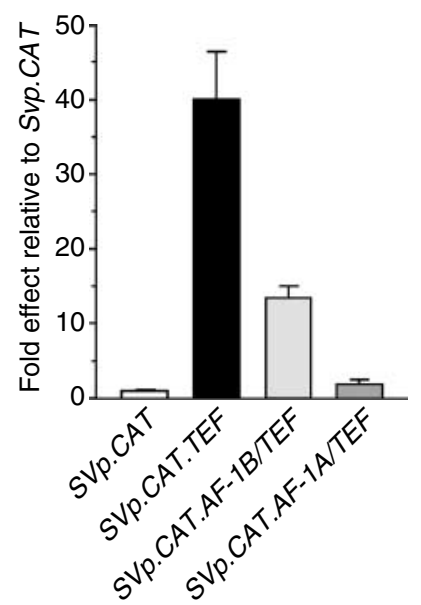

Figure 2 Comparison of the effects of the AF-1A and AF-1B regions on TEF-1 enhancer activity. Placental choriocarcinoma cells (JEG-3) were transiently transfected with CAT reporter gene constructs, directed by the SV40 promoter and containing the $22 \mathrm{bp}$ high affinity TEF site in combination with the AF-1 regions from either the $C S-A(A F-1 A)$ or the $C S-B(A F-1 B)$ gene. While AF-1B showed significant repression of TEF-induced activity $(n=23-30, P<0.05), A F-1 A$ completely abolished it $(n=6-23, P<0.001)$. A diagram of the basic structure of the SVp.CAT.AF-1.TEF-1 construct has been published previously (Lytras et al. 1996). 


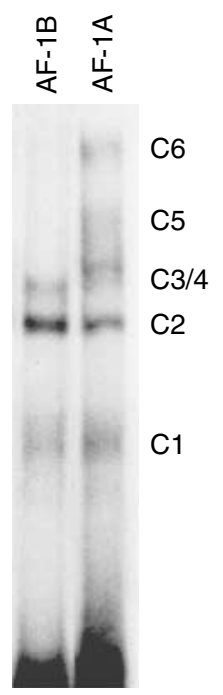

Figure 3 Electrophoresis mobility shift patterns of the AF-1A and $A F-1 B$ regions. Nuclear extracts from placental choriocarcinoma JEG-3 cells were used to compare the EMSA patterns obtained with radiolabeled $A F-1 A$ and $A F-1 B$ regions, as indicated. EMSA experiments were carried out as described in the section Materials and methods, and the binding reactions resolved on a nondenaturing $4 \%$ acrylamide gel. Complexes of various mobilities observed with either or both oligonucleotide probes are indicated (C1-C6).

additional lower mobility complexes were readily detected with the AF-1A alone (C4, C5, and C6). However, a lower mobility complex migrating similarly to $\mathrm{C} 6$ was also observed in prolonged exposures of AF-1B EMSAs (not shown). We used competition assays to examine the specificity and affinities of the observed complexes as well as to assess the possibility that the absence of lower mobility complexes from the AF-1B region may reflect different affinities of the $\mathrm{AF}-1 \mathrm{~A}$ and AF-1B regions for some of the lower mobility complexes (Fig. 4). For AF-1B complexes, AF-1A competed for C2 and weakly for C3. For AF-1A complexes, AF-1B competed efficiently for C2, and, with lower efficiency, also for the lower mobility C5 and C6. In contrast, the $\mathrm{AF}-1 \mathrm{~B}$ region was unable to compete for $\mathrm{C} 3$ and $\mathrm{C} 4$ formed on the AF-1A region.

We showed previously that the TEF oligonucleotide, corresponding to nts 117-139, competes for some low but not high affinity complexes formed on the AF-1B region (Lytras et al. 1996). In this study, we compared competition of complexes formed on AF-1A versus AF-1B regions by the TEF oligonucleotide. For AF-1A complexes, C2 and C5 were competed for most effectively by AF-1A, but also by TEF, which was in turn a more efficient competitor than AF-1B. TEF oligonucleotides were also able to compete, but less effectively, for C6 but did not compete for C1, C3, and C4. For AF-1B complexes, TEF competed weakly for C2 but not for C3.

\section{Putative C/EBP and Ets sites are present in the AF-1B and/or the AF-1A region}

Using available transcription factor databases, we searched the modulatory domains of the $C S-A$ and $C S-B$ enhancers for putative transcription factor recognition sites (core $100 \%$, overall similarity $>75 \%$; Fig. 5). A putative Elk-1 site (100\% core, $93 \%$ overall similarity), an Ets family member, was identified in the reverse orientation in the AF- $1 \mathrm{~A}$ region. Because of a single nucleotide discrepancy in the $\mathrm{AF}-1 \mathrm{~B}$ region relative to AF-1A, the core of the Elk-1 site present in AF-1A (CGGA) is absent in the AF-1B region (CtGA). A putative site for $\mathrm{C} / \mathrm{EBP}$ was identified in both the $\mathrm{AF}-1 \mathrm{~A}$ and $\mathrm{AF}-1 \mathrm{~B}$ regions. The $\mathrm{C} / \mathrm{EBP}$ site overlaps the Elk-1 site in AF-1A and, because of the same single nucleotide difference, is not identical in AF-1B (100\% core, 79 and $88 \%$ overall similarity for the AF-1A and AF-1B regions respectively).

\section{Elk-1 overexpression results in modification of DNA-protein interactions on the AF-1A but not the AF-1B region}

Following the identification of the putative Elk-1 binding site in AF-1A, nuclear extracts were prepared from JEG-3 cells transfected with expression vectors carrying the cDNAs for various Ets family members (Ets-1, Ets-2, Elf-R, Elf-1, and Elk-1), and were examined in EMSAs using the AF-1A and, as a comparison, the AF-1B region (Fig. 6). A high mobility complex (HMC) and a lower mobility complex with similar mobility to C4 were observed in Elk-1 extracts but not with any of the other Ets family members on the AF-1A region (Fig. 6A). In contrast, no modification of the mobility pattern was observed with the AF-1B region. In parallel, a reduction of $\mathrm{C} 5$ on the AF-1A region was also observed with Elk-1 overexpression. The specificity and affinity of the Elk-1induced complexes on AF-1A but not AF-1B sequences, was further characterized by competition with either unlabeled AF-1A or AF-1B oligonucleotide competitors (Fig. 6B). Both Elk-1-induced complexes (HMC, C4) were readily competed by AF-1A but not AF-1B competitor.

To confirm the participation of Elk-1 in the C4-like complex formed on the AF-1A region, nuclear extracts from JEG-3 cells transfected with the Elk-1 expression vector (Elk-1 is FLAG-tagged), were preincubated with monoclonal antibodies against the FLAG epitope (Fig. 7). A 'supershift' of C4 was observed with nuclear extracts from JEG-3 cells that were transfected with but not without the Elk-1 expression vector. No distinct 'supershift' or competition of HMC was observed with anti-FLAG antibodies. This complex might be induced by Elk-1 but not comprised of Elk-1, and thus may or may not be important for the formation of other AF-1 complexes. It is also possible that conformational changes may interfere with accessibility of the FLAG 


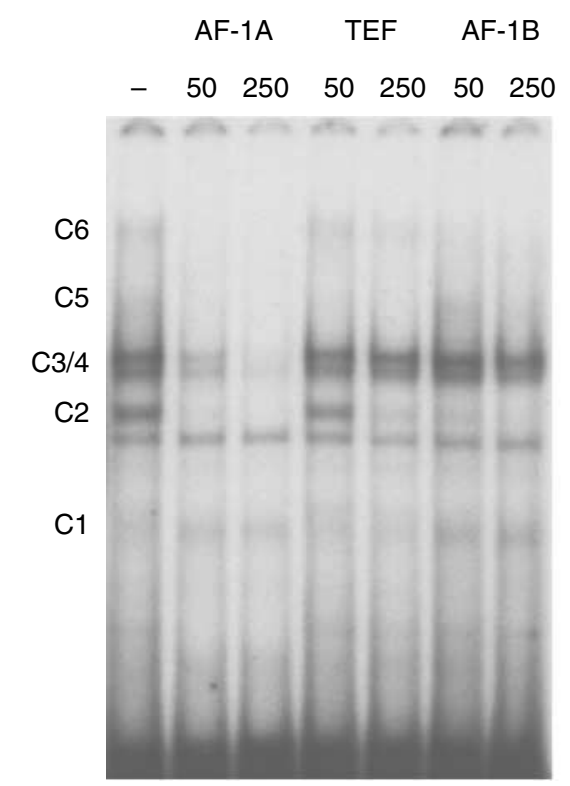

AF-1A probe

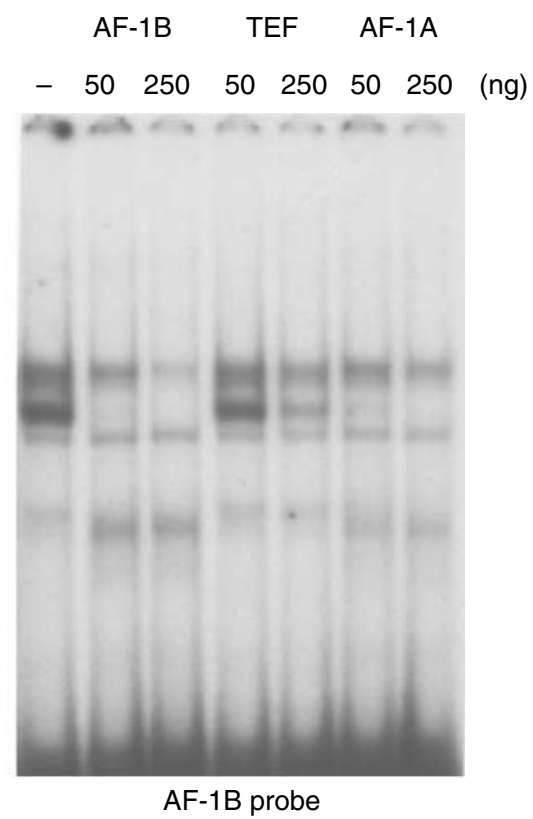

AF-1B probe

Figure 4 Electrophoresis mobility shift patterns of the AF-1 regions combined with competition assays with AF-1A, AF-1B, and TEF oligonucleotides. Competition assays using JEG-3 nuclear extracts and increasing amounts of unlabeled competitor oligonucleotides. The identity of the radiolabeled probe is indicated underneath the figure; amount (ng) and the competitors used are shown at the top. Apart from the specific complexes, an apparently non-specific/low affinity complex is observed migrating slightly faster than $\mathrm{C} 2$ with both $\mathrm{AF}-1 \mathrm{~A}$ and $\mathrm{AF}-1 \mathrm{~B}$ probes. In general, minor differences such as observed in the binding patterns in Fig. 4 compared with Fig. 3 can be attributed to minor modifications of the experimental conditions, including use of different batches and amounts of nuclear extracts or incubation (room) temperature. Higher amounts of nuclear extracts tend to increase the relative intensity of lower mobility complexes (rather including more associated factors); in Fig. 3, the AF-1A probe seems to be associated with more pronounced lower mobility complexes (mainly C6), while in Fig. 4, the AF-1A probe seems to be associated with relatively higher intensity of $\mathrm{C} 2$ and $\mathrm{C} 3 / 4$.

tag, and thus allow for differential recognition of Elk-1FLAG associated with HMC versus C4. Finally, it could be a simpler complex resulting from dissociation of a larger complex after association of Elk-1 with AF-1A; for example, Elk-1 displaced a factor that can still associate with AF-1 as a monomer.

\section{$\mathrm{C} / \mathrm{EBP} \propto$ overexpression results in the formation of a 'novel' complex on the AF-1B region}

Nuclear extracts were prepared from JEG-3 cells transfected with control vector (RcCMV) and expression vectors carrying the cDNAs for $\mathrm{C} / \mathrm{EBP} \alpha$ or $\mathrm{C} / \mathrm{EBP} \beta$ (FLAG-tagged) and were examined in EMSAs using the $\mathrm{AF}-1 \mathrm{~A}$ or the $\mathrm{AF}-1 \mathrm{~B}$ region as a probe. The patterns obtained with both $\mathrm{AF}-1$ regions appeared modified by $\mathrm{C} / \mathrm{EBP}$ overexpression (Fig. 8A). C/EBP $\alpha$ overexpression resulted in the formation of a 'novel' complex on AF-1B, migrating similarly to $\mathrm{C} 5$ formed on AF-1A with control extracts. This suggested that $\mathrm{C} / \mathrm{EBP} \alpha$ might physically participate in the formation of the novel C5 complex on AF-1B. To directly determine the presence of $\mathrm{C} / \mathrm{EBP} \alpha$ in this complex, monoclonal antibodies against the FLAG epitope were used. A 'supershift' of the novel complex was observed (Fig. 8B). No 'supershift' was produced in the absence of $\mathrm{C} / \mathrm{EBP} \alpha$ overexpression or when an anti-Rb monoclonal antibody was used as control.

We tested the effectiveness of the AF-1B and AF-1A unlabeled regions to compete for the novel AF-1B C5 complex (Fig. 9). Indeed C5 was readily competed by both AF-1B and AF-1A oligonucleotides.

\section{Elk-1 overexpression in JEG-3 cells modifies the relative CS-A versus CS-B enhancer activity}

We examined the possible functional significance of these new complexes on the basis of differential Elk-1 effects on the $C S-A$ versus the $C S-B$ enhancers. Initially, we examined the effects of Elk-1 overexpression on the activity of $C S p$.CAT constructs containing either the $C S-A$ or the $C S-B$ enhancer (Fig. 10A). Interestingly, Elk-1 repressed the activity of the $C S$ promoter alone 


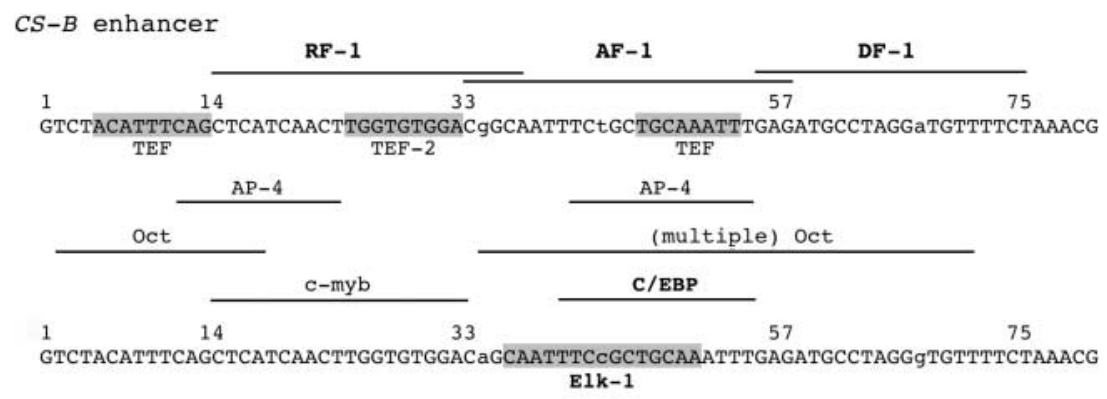

\footnotetext{
CS-A enhancer
}

Figure 5 Putative transcription factor recognition sites in the modulatory domains of the $C S-A$ and $C S-B$ enhancers. Putative transcription factor recognition sites were identified using transcription factor databases (core $100 \%$, overall similarity $>75 \%$ ). TEF-related sites, as reported by others (Jacquemin et al. 1997, Jiang et al. 1997) are highlighted in the $C S-B$ enhancer sequence. A putative Elk-1 site is present in the $C S-A$ enhancer (highlighted) but not in the $C S-B$ enhancer sequence. Binding sites common to both regions are indicated between the two sequences. Nucleotide discrepancies between $C S-B$ and $C S-A$ are indicated in lower case.

(CSp.CAT) resulting in a remaining activity of $44.8 \%$ $(n=5, P<0 \cdot 001)$. A CSP.CAT.CS-Benh construct was also repressed in an identical manner with a remaining activity of $43 \cdot 6 \% \quad(n=5, P<0 \cdot 005)$. However, Elk-1 overexpression repressed more strongly the CSp.CAT.CS-Aenh resulting in a remaining activity $26 \cdot 4 \%(n=5, P<0 \cdot 001)$. The difference between the percentage of the remaining activity of the CSp.CAT or the CSp.CAT.CS-Benh constructs and the CSp.CAT.CSAenh construct was statistically significant $(n=5$, $P<0 \cdot 001)$. Thus, in this context, relative to CSp.CAT, the $C S-A$, but not the $C S-B$, enhancer demonstrated a negative effect in response to Elk-1 overexpression.

\section{C/EBP $\alpha$ and C/EBP $\beta$ overexpression in JEG-3 cells represses the activity of the CSp, but increases CS-B and CS-A enhancer activities resulting in a net increase in the activity of a CSp.CAT.CS-Benh construct but not of a CSp.CAT.CS-Aenh construct}

Given the identification of $\mathrm{C} / \mathrm{EBP}$ binding sites, the effect of $\mathrm{C} / \mathrm{EBP} \alpha$ or $\mathrm{C} / \mathrm{EBP} \beta$ overexpression on the activity of the $496 \mathrm{bp}$ CSp fragments was examined in the presence and absence of either the $C S-A$ or the $C S-B$ $241 \mathrm{bp}$ enhancers (Fig. 10B). Both C/EBP $\alpha$ and $\mathrm{C} / \mathrm{EBP} \beta$ resulted in increased CSp.CAT.CS-Benh construct activity (by $64 \cdot 3$ and $71 \cdot 7 \%$, respectively, $n=4$,
A

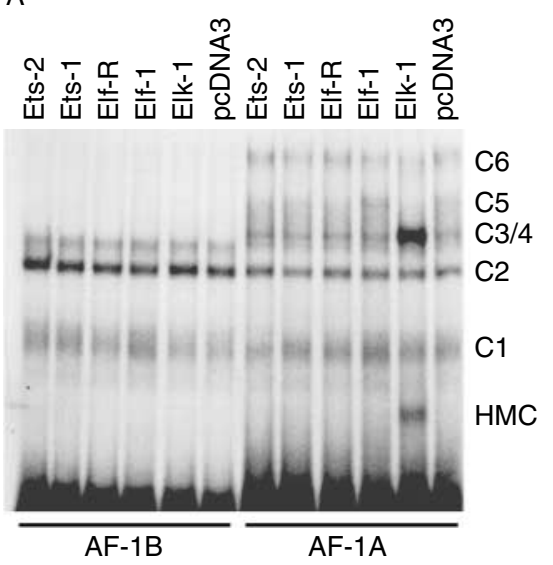

B

$\frac{\text { Control }}{\text { AF-1A }} \frac{\text { Elk-1 }}{\text { AF-1A AF-1B }}$

- $1050250-10502501050250$ (ng)

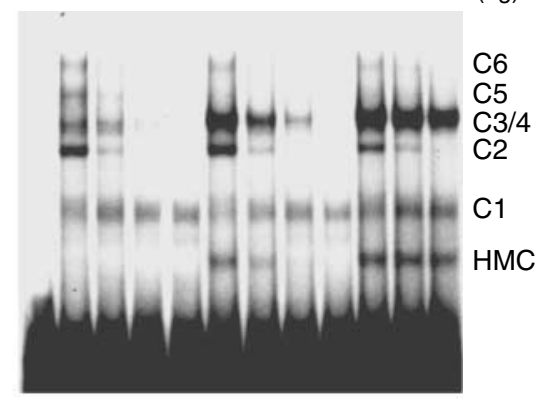

AF-1A

Figure 6 Effect of Elk-1 overexpression on DNA-protein interactions in the AF-1 regions. $(A)$ Nuclear extracts $(5 \mu \mathrm{g})$ were prepared from JEG-3 cells transfected with expression vectors carrying the cDNAs for Ets family members (Ets-1, Ets-2, Elf-R, Elf-1, and Elk-1) and were examined in $\mathrm{EMSAs}$ using $\mathrm{AF}-1 \mathrm{~A}$ and $\mathrm{AF}-1 \mathrm{~B}$ radiolabeled oligonucleotides (indicated below the figure). A high mobility complex (HMC) and a lower mobility complex either identical to or with similar mobility to C4 were observed in Elk-1 extracts but not with any of the other Ets family members on the $A F-1 A$ region. $(B)$ Competition assays using radiolabeled $A F-1 A$, and $\mathrm{AF}-1 \mathrm{~A}$ or AF-1B competitor (ng) as indicated. Nuclear extracts were prepared from JEG-3 cells transfected with the Elk-1 expression vector (Elk-1) or with pcDNA (Control). 


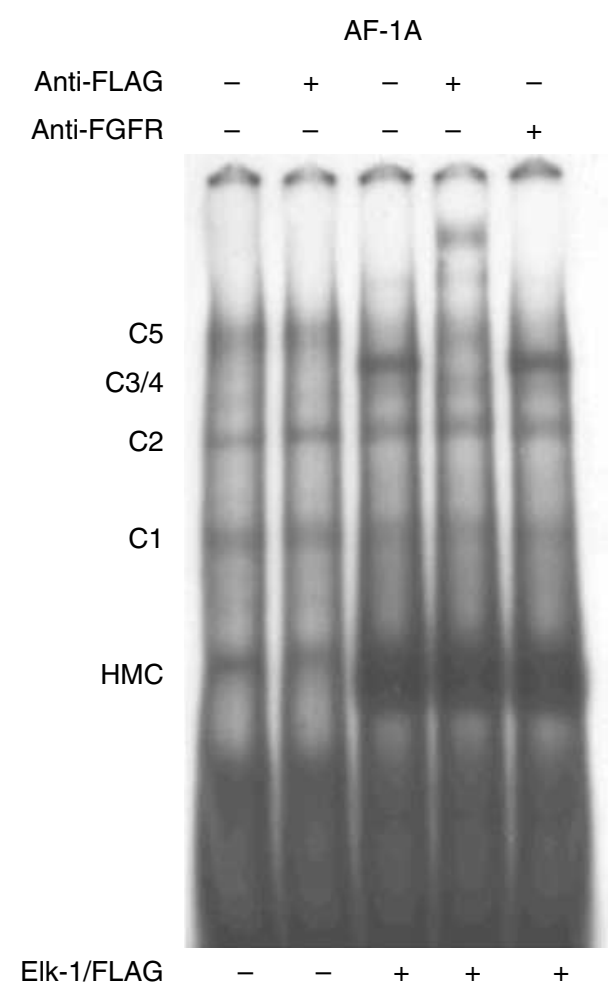

Figure 7 Electrophoresis mobility 'supershift' assays for the detection of Elk-1-related complexes with AF-1A. Nuclear extracts $(6 \mu \mathrm{g})$ from JEG-3 cells transfected with the same Elk-1 expression vector used in Fig. 6 (Elk-1+), or with pcDNA as a control (Elk-1-), were preincubated with monoclonal antibodies (M2, Sigma) against the FLAG epitope (anti-FLAG) or against FGFR-1 (anti-FGFR, as a negative control). Following binding to radiolabeled $\mathrm{AF}-1 \mathrm{~A}$, samples were resolved on a non-denaturing $5 \%$ polyacrylamide gel. Complexes are labeled to correspond to previous figures.

$P<0.005)$ in spite of a strong negative effect on independent CSp activity (approximately eightfold or $>87 \%$ repression of control activity, $n=4, P<0 \cdot 001$ ). This is reflected in the activity of the $C S-B$ enhancer (expressed as the fold difference of the activity of the CSp.CAT.CS-Benh over the activity of the CSp.CAT) that increased from $\sim 12$ - to $\sim 330$-fold. In contrast, the $C S$ $A$ enhancer was unable to fully compensate for the repression of the CSp by either $\mathrm{C} / \mathrm{EBP} \alpha$ or $\mathrm{C} / \mathrm{EBP} \beta$. This resulted in a net $\sim 75 \%$ reduction in the activity of CSp.CAT.CS-Aenh $(n=2, P<0 \cdot 01)$. It has to be noted, however, that the activity of the $C S-A$ enhancer, (expressed as the fold difference of the activity of the CSp.CAT.CS-Aenh over the activity of the CSp.CAT) increased from $\sim 1 \cdot 5$-fold under control conditions to $\sim 4 \cdot 4$-fold in the presence of $\mathrm{C} / \mathrm{EBPs}$. Thus, $\mathrm{C} / \mathrm{EBP} \alpha$ and $\mathrm{C} / \mathrm{EBP} \beta$ appeared to increase $C S-B$ enhancer activity much more effectively than $C S-A$ enhancer activity, increasing the fold-difference between the activities of these enhancer regions by over an order of magnitude (from 7.9-fold under control conditions to $81 \cdot 9$ - and 87 -fold in the presence of $\mathrm{C} / \mathrm{EBP} \alpha$ or $\mathrm{C} / \mathrm{EBP} \beta$ respectively).

\section{C/EBP $\beta$ associates with the CS-A and CS-B genes and enhancer regions, in situ}

An unbiased ChIP on chip tiling array for chromosome 17 was used to assess whether $\mathrm{C} / \mathrm{EBP} \beta$ associates with $C S-A$ and $C S-B$ sequences in the context of human term placenta chromatin. C/EBP $\beta$ was targeted for examination based on its high level of placental expression, particularly during late pregnancy (Bamberger et al. 2004). C/EBP $\beta$ 'intervals', indicating transcription factor binding in situ, were detected in both the $C S-A$ and $C S-B$ genes (Fig. 11). The modulatory domains of both the CS-A and CS-B enhancer regions were found at the borders of $\mathrm{C} / \mathrm{EBP} \beta$ 'intervals' that extended from the enhancer regions to $\sim 3312$ and 3311 nts downstream of their respective transcription initiation sites (Table 1). In both cases 'peak' regions were found a few hundred bp upstream of these $3^{\prime}$ enhancers more proximal to the coding region of the gene.

In addition, differential spreads of the $C S-A$ and $C S-B$ $\mathrm{C} / \mathrm{EBP} \beta$ intervals over the enhancer regions were observed. In the case of the $C S-A$ gene, the $\mathrm{C} / \mathrm{EBP} \beta$ interval starts at the core of the enhancer modulatory domain and extends upstream toward the coding region of the gene, and in the opposite direction relative to the main TEF-1 site which lies downstream of the modulatory domain (Fig. 11). Indeed, in the CS-A gene, the $\mathrm{C} / \mathrm{EBP} \beta$ interval spans from nts 59323740 to 59325870 (Table 1) extending upstream toward the $C S$ $A$ gene-coding region. As the overlapping Elk-1/C/EBP site in the modulatory domain of the CS-A enhancer spans nts 59323721-59323739, the detected C/EBP interval starts just upstream of this binding site (Fig. 11). Putative C/EBP sites are present upstream of the Elk-1 site (not shown) of which the most proximal overlaps with the c-myb site shown in Fig. 5 . In contrast to CS-A, for the $C S-B$ gene, the $\mathrm{C} / \mathrm{EBP} \beta$ interval spans from nts 59300535 to 59303012 (Table 1) and includes the full length $241 \mathrm{bp}$ enhancer, and thus the 'main' TEF-1 site, and similarly extends upstream toward the $C S-B$ coding region.

\section{Discussion}

In previous studies, we assessed the functional differences between the $C S-A$ and $C S-B$ enhancers to gain insight into the mechanism by which placental enhancer function is regulated (Lytras \& Cattini 1994, Lytras et al. 1996, Jin et al. 2009). In particular, in comparison to the $C S-B$ enhancer, the $C S-A$ enhancer bears nucleotide substitutions that render it inactive in 
B
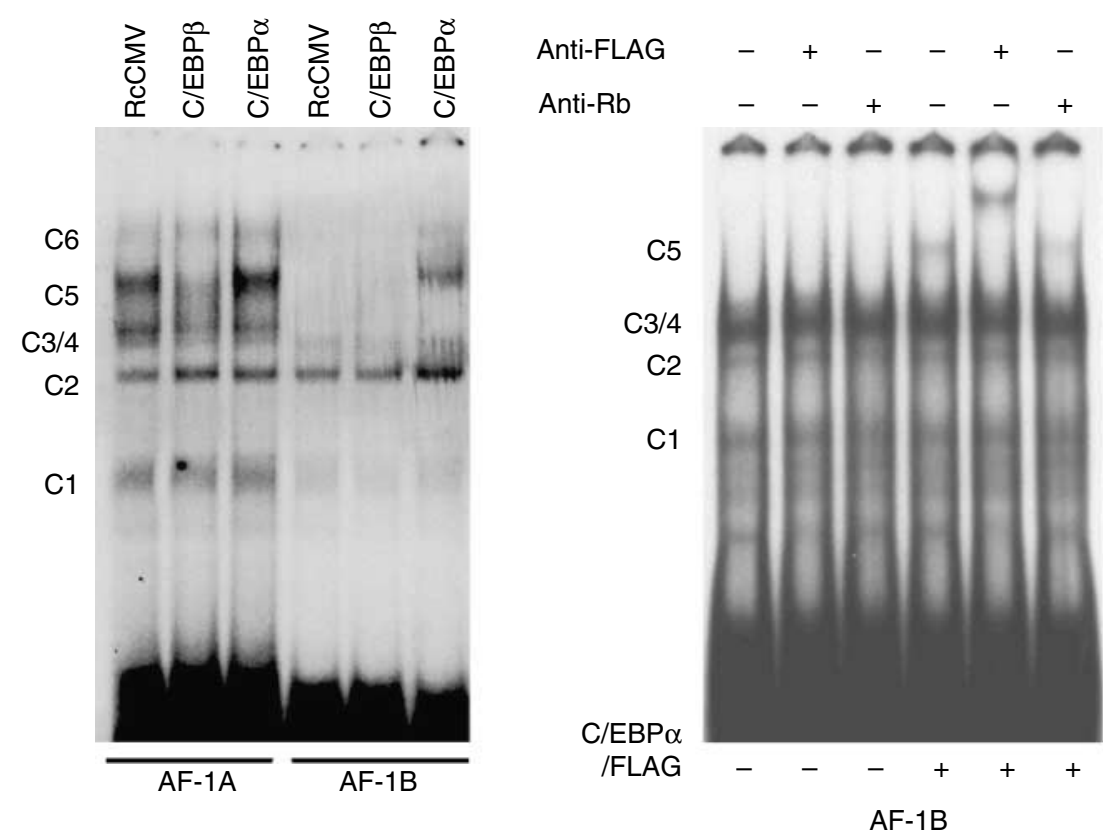

Figure 8 Effects of $\mathrm{C} / \mathrm{EBP} \alpha$ and $\mathrm{C} / \mathrm{EBP} \beta$ overexpression on the DNA-protein interactions on the AF-1 regions and electrophoresis mobility supershift assays for the detection of $\mathrm{C} / \mathrm{EBP} \alpha$-related complexes on AF-1A. (A) Nuclear extracts $(5 \mu \mathrm{g})$ from JEG-3 cells transfected with control expression vector (RcCMV) or expression vectors for $\mathrm{C} / \mathrm{EBP} \alpha$ or $\mathrm{C} / \mathrm{EBP} \beta$ (as indicated) were examined in EMSAs using the AF-1A or the AF-1B radiolabeled probe (indicated below the figure). Binding reactions were resolved on a nondenaturing $4 \%$ polyacrylamide gel. Complexes $(\mathrm{C} 1-\mathrm{C} 6)$ are labeled to correspond to previous figures. (B) Nuclear extracts from control $(-)$ and C/EBP $\alpha$-overexpressing $(+)$ JEG-3 cells were preincubated with monoclonal antibodies against the FLAG epitope (antiFLAG) or with commercial anti-human monoclonal antibodies (anti-Rb) as a control. Subsequent binding reactions using radiolabeled $\mathrm{AF}-1 \mathrm{~B}$ were then resolved on a nondenaturing $5 \%$ polyacrylamide gel.

transfected choriocarcinoma cells in vitro (Lytras et al. 1996). These substitutions are found in sequences outside the minimal enhancer region that is identical in the two enhancers (nts 117-139) and has been shown to interact with the TEF-1 and TEF-5 members of the TEA domain family. We have examined the structural and functional implications of these few nucleotide differences with an aim to identifying proteins different from TEFs that may have a regulatory role, having differential effects on $C S$ - $A$ versus $C S$ - $B$ enhancer function. We have now identified binding sites for the $\mathrm{C} / \mathrm{EBP}$ and Ets families of transcription factors, in areas distinct from the minimal enhancer element, and with small nucleotide differences between them. Furthermore, we show that members of these families can differentially modify $C S-A$ and $C S-B$ enhancer activities. Finally, observations made from ChIP on chip tiling array assay of human term placenta chromatin, are consistent with $\mathrm{C} / \mathrm{EBP} \beta$ binding to the CS 'enhancer' regions, and even suggest differential occupancy of the $C S-A$ and $C S-B$ sequences. This clearly increases confidence that the CS 'enhancer' regions are sites of regulatory significance in vivo.

There are only six nucleotide differences between the 241 bp $C S-A$ and $C S-B$ enhancer regions, with three in the modulatory domain, including two in AF-1 and one in DF-1 (Lytras et al. 1996). These can be likened to point mutations, and thus highly specific indicators of the sequences and by extension the elements that confer the CS-Aenh versus CS-Benh differences, as suggested for AF-1 in response to Elk-1 and C/EBP in this study. Insertion of AF-1A upstream of the TEF element conferred a stronger repression than AF-1B resulting in complete loss of minimal TEF enhancer activity (Fig. 2). This difference in the effects of AF-1A versus $\mathrm{AF}-1 \mathrm{~B}$ is consistent with the generation of enhancer activity by the mutational 'repair' of AF-1A to resemble AF-1B in the context of the $241 \mathrm{bp} \mathrm{CS-A}$ enhancer (Lytras et al. 1996). It has been suggested that the combined AF-1 and DF-1 regions may represent lower affinity TEF binding sites (Jiang \& Eberhardt 1994, 1996). If so, this would provide an explanation for 


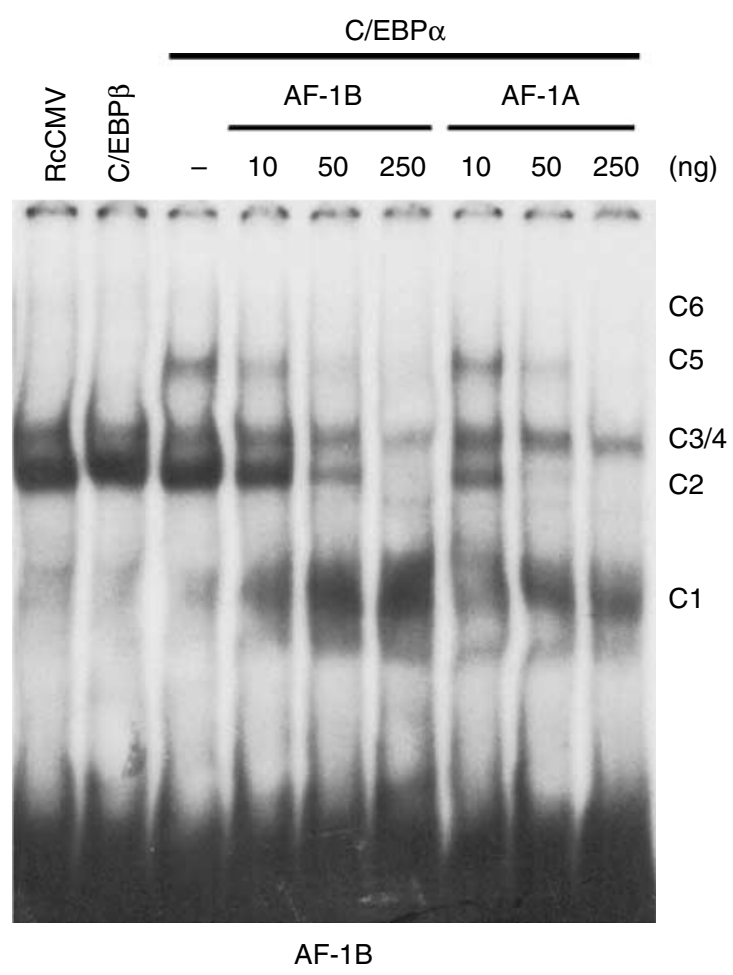

Figure 9 Competition assays for the novel $C / E B P \alpha$-induced complex formed on the AF-1B region with $\mathrm{AF}-1 \mathrm{~B}$ and $\mathrm{AF}-1 \mathrm{~A}$ unlabeled competitors. Nuclear extracts from JEG-3 cells transfected with control vector (RcCMV) or with expression vectors for $\mathrm{C} / \mathrm{EBP} \alpha$ or $\mathrm{C} / \mathrm{EBP} \beta$ (as indicated) were used in competition EMSA with radiolabeled AF-1B. The nanogram amounts of cold AF-1A or AF-1B competitor oligonucleotides are indicated. The migrating positions of complexes $\mathrm{C} 1-\mathrm{C} 6$ are also labeled to correspond to previous figures.

the synergistic effect of combining the AF-1/DF-1 region and the minimal TEF element in the context of the 241 bp CS-B enhancer (Jiang \& Eberhardt 1994, 1996, Lytras \& Cattini 1994). However, in our studies the AF-1 region, without DF-1, represses TEF effects. It is possible that the AF-1 region alone does not allow TEFs to bind or make a functional interaction with the high affinity TEF element.

An alternative possibility is that additional factors interact with the AF-1 and inhibit TEF action. This is supported by the distinct EMSA patterns observed with AF-1A and AF-1B elements (Fig. 3), and by incomplete overlap between these DNA fragments in competition assays (Fig. 4). A putative $\mathrm{C} / \mathrm{EBP}$ binding site was identified in both regions (Fig. 5) and evidence of binding was obtained by EMSA (Figs 8 and 9). In the case of $\mathrm{AF}-1 \mathrm{~B}$, a new $\mathrm{C} / \mathrm{EBP} \alpha$ complex (C5) was generated with $\mathrm{C} / \mathrm{EBP} \alpha$ overexpression and was competed by both AF-1A and AF-1B oligonucleotides. In contrast, only minor changes were observed with $\mathrm{AF}-1 \mathrm{~A}$, however, this is to be expected as a band with the same mobility as C5 was observed with control (JEG-3) nuclear protein (Fig. 8). Thus, the structural data are consistent with $\mathrm{C} / \mathrm{EBP}$ interaction with $\mathrm{AF}-1 \mathrm{~B}$ as well as AF-1A, which is naturally 'mutated' at two nucleotides in the context of the $C S$-A enhancer (Fig. 5) and, notably, differs functionally from AF-1B. This functional difference could be explained by the binding of different factors in the AF-1A and AF-1B sites. As a result of a single bp difference that disrupts the Ets core, AF-1A but not AF-1B binds Elk-1, which can be competed by AF-1A but not AF-1B oligonucleotides in an EMSA (Figs 6 and 7). The presence of this Ets site may result either in facilitation or in competition of C/EBP-related complexes formed on AF-1A, establishing an 'Ets-directed' modulatory switch on $C S$ enhancer function. Alternatively, differential affinity for $\mathrm{C} / \mathrm{EBP}$ binding, differential conformation of $\mathrm{C} / \mathrm{EBP}$ complexes or even binding of factors other than Ets could explain the functional difference between the $\mathrm{AF}-1 \mathrm{~A}$ and $\mathrm{AF}-1 \mathrm{~B}$ sites.
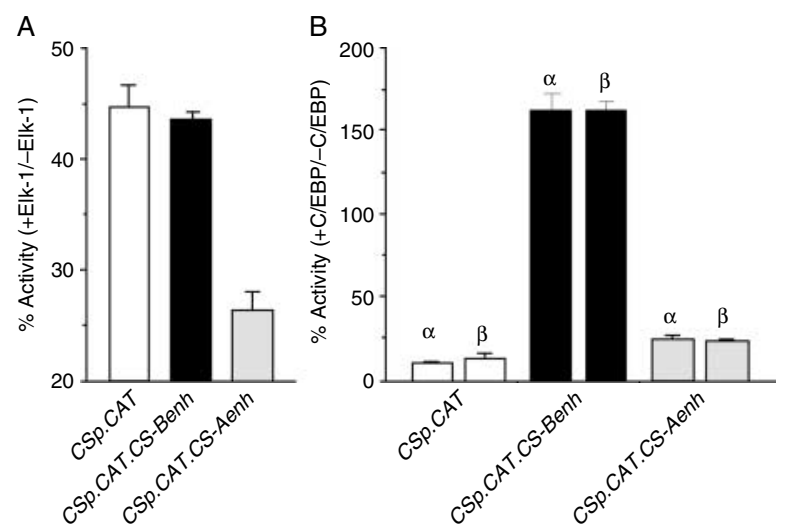

Figure 10 Effects of Elk-1 and C/EBP overexpression on the activity of constructs containing either the $C S-A$ or the $C S-B$ enhancer. (A) Elk-1 overexpression repressed the activity of the CS promoter alone (CSp.CAT) resulting in a remaining activity of $44.8 \%(n=5, P<0.001)$, and the activity of CSp.CAT constructs containing either the $C S-A$ or the $C S-B$ enhancer. A CSp.CAT.CSBenh construct was repressed in an identical manner (remaining activity $43.6 \%)(n=5, P<0.005)$. However, the CSp.CAT.CSAenh construct was repressed more strongly by Elk-1 overexpression resulting in a remaining activity of $26.4 \%(n=5$, $P<0.001$ ). The difference between the percentage of the remaining activity of the CSp.CAT or the CSp.CAT.CS-Benh constructs and the CSp.CAT.CS-Aenh construct was statistically significant $(n=5, P<0.001)$. (B) C/EBP $\alpha(\alpha)$ or C/EBP $\beta(\beta)$ co-transfection $(5 \mu \mathrm{g})$ resulted in a strong negative effect on independent CS promoter activity (approximately eightfold or 88.5 and $87 \cdot 1 \%$ repression of control activity, by $\mathrm{C} / \mathrm{EBP} \alpha(n=4)$ and $\mathrm{C} / \mathrm{EBP} \beta(n=4)$ respectively $(P<0.001))$. However, the presence of the $C S-B$ enhancer reversed this negative effect and the CSp.CAT.CS-Benh construct activity increased by 64.3 and $71 \cdot 7 \%$, in the presence of C/EBP $\alpha(n=4)$ and C/EBP $\beta(n=4)$ respectively $(P<0.005)$. In contrast, the CS-A enhancer was unable to compensate for the repression of the CS promoter by $\mathrm{C} / \mathrm{EBP} \alpha(n=2)$ and $\mathrm{C} / \mathrm{EBP} \beta(n=2)$, resulting in a net $\sim 75 \%$ reduction in CSp.CAT.CS-Aenh construct activity $(P<0.01)$. 


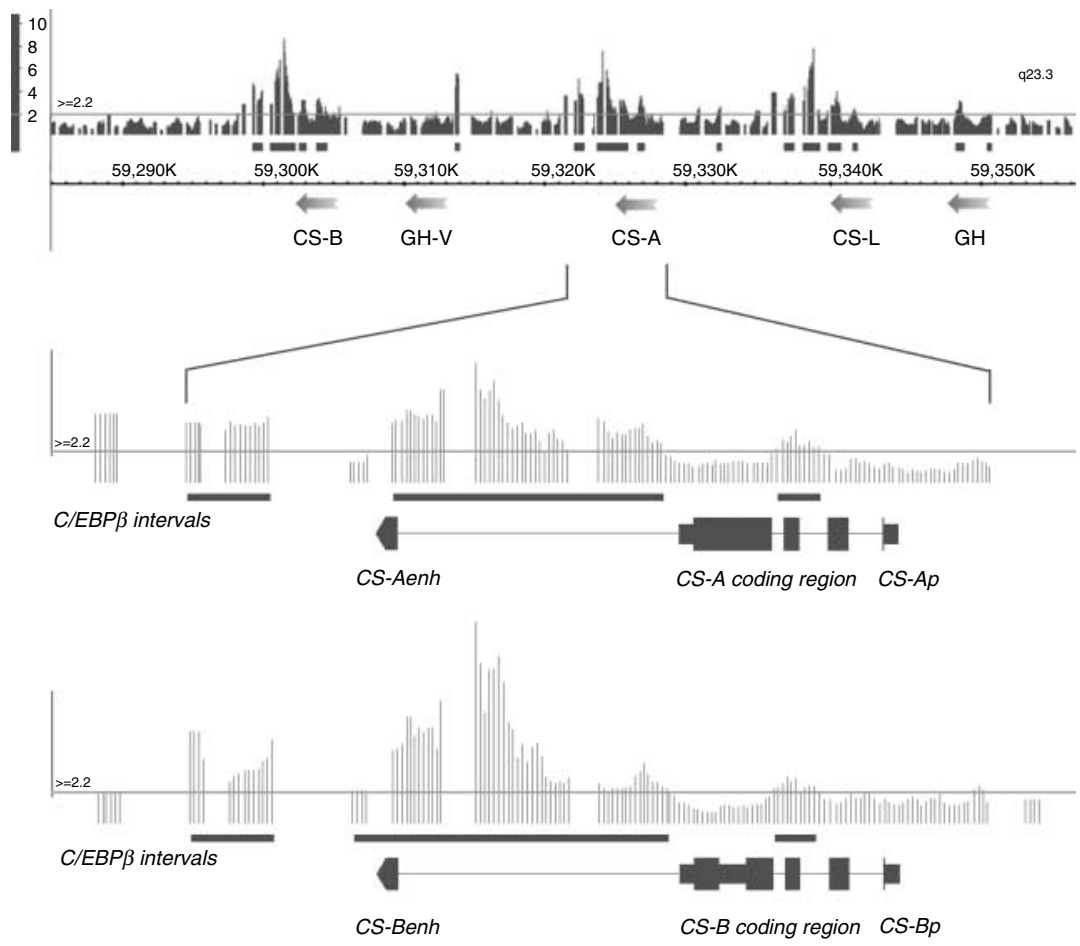

Figure 11 Association of C/EBP $\beta$ with the $C S-A$ and $C S-B$ genes in human term placenta chromatin. Map of the peak intensities for C/EBP $\beta$ binding across all five members of the human $\mathrm{GH} / \mathrm{CS}$ gene family on chromosome 17 in human term placenta as detected by ChIP on chip analysis. The line running horizontally through each set of 'peaks' represents the threshold applied to peak intensities based on normalization against input DNA array data to obtain intervals for the C/EBP $\beta$ ChIP DNA (Materials and methods). Thick horizontal lines indicate $\mathrm{C} / \mathrm{EBP} \beta$ intervals. The positions and $5^{\prime}-3^{\prime}$ directions of the five $\mathrm{GH} / \mathrm{CS}$ genes are indicated under the low resolution map of the GH/CS locus. Nucleotide numbering corresponds to human chromosome 17 sequences as included in the University of California Santa Cruz (UCSC) Genome Browser (http://genome.ucsc.edu). The CS-A and $C S-B$ enhancer (enh) as well as promoter (p) and coding regions are shown under a higher resolution map of the intervals for each of the $C S-A$ and $C S-B$ genes, to allow better alignment of intervals and regulatory sequences. See text in Results and Table 1 for further details regarding exact numbering of the interval sequences.

Regulation through interaction of Ets/Elk-1 and $\mathrm{C} / \mathrm{EBPs}$, and specifically with $\mathrm{C} / \mathrm{EBP} \alpha$ and $\beta$, have been reported, and these data suggest multiple mechanisms for affecting promoter activity. These include acting through independent DNA elements, acting synergistically, participating through proteinprotein interaction, and contributing to efficient expression as well as inducing hormone (insulin) responsiveness (Hanlon et al. 2000, Jacob \& Stanley 2001, Lin et al. 2005, Hung et al. 2010). Our functional data give insight into the possible interactions of $\mathrm{C} / \mathrm{EBP}$ and Elk-1 with their overlapping sites. Interestingly, Elk-1 overexpression represses CSp.CAT activity. Importantly, it affects the $C S-A$ and $C S-B$ enhancers differently as the $C S-A$, but not the $C S-B$, enhancer responded negatively to Elk-1 overexpression (Fig. 10A). Like Elk-1, C/EBP $\alpha$ or $\beta$ overexpression also represses CSp.CAT activity in JEG-3 cells. Unlike the case with Elk-1, however, the presence of the $C S-B$ enhancer region reverses the effect of $\mathrm{C} / \mathrm{EBP}$ overexpression and in fact results in enhanced CSp.CAT. $C S$-Benh activity. In contrast, the $C S$ - $A$ enhancer region compensates only slightly with the net effect still being repression (Fig. 10B). It is possible that in the presence of the $C S-B$ enhancer, the interaction of $\mathrm{C} / \mathrm{EBP}$ proteins with the promoter is neutralized by factors other than C/EBPs; thus, a 'competition' occurs between enhancer-related complexes and C/EBP proteins. Alternatively, enhancer complexes that include $\mathrm{C} / \mathrm{EBP}$ proteins interact with the $\mathrm{C} / \mathrm{EBP}$ complexes in the promoter region. Certainly putative $\mathrm{C} / \mathrm{EBP}$ elements can be detected by sequence analysis within the first $500 \mathrm{bp}$ upstream of the $C S-A$ and $C S-B$ transcription initiation sites (not shown), and elements $>1 \mathrm{~kb}$ upstream have been reported (Stephanou \& Handwerger 1995). In either case, enhancer sequences 
Table 1 CCAAT/enhancer-binding protein $\beta$ (C/EBP $\beta)$ intervals on the GH/CS locus on chromosome 17 as detected by ChIP on chip tiling array assay. Nucleotide numbering corresponds to human chromosome 17 sequences as included in the University of California Santa Cruz (UCSC) Genome Browser (http://genome.ucsc.edu). Intervals on the CS-A (2130 nts) and CS-B (2477 nts) genes that include enhancer sequences are indicated (bold). The equivalent CS-L interval that differs in length (1045 nts) is also indicated

\begin{tabular}{|c|c|c|c|c|c|c|}
\hline End & Length & Probes & Peaks & Peak center & Gene list & Distance to start \\
\hline 59299929 & 668 & 14 & 3 & 59299309 & CS-B & 5512 \\
\hline 59303012 & 2477 & 53 & 1 & 59301510 & CS-B, GH-V & 3311,11445 \\
\hline 59304164 & 340 & 10 & 1 & 59303944 & CS-B, GH-V & 877,9011 \\
\hline 59313933 & 277 & 8 & 4 & 59313795 & CS-B, GH-V & $(-) 8974,(-) 840$ \\
\hline 59317627 & 237 & 7 & 1 & 59317614 & $\mathrm{GH}-\mathrm{V}, \mathrm{CS}-\mathrm{A}$ & $(-) 4659,10105$ \\
\hline 59322799 & 668 & 15 & 1 & 59322786 & $\mathrm{GH}-\mathrm{V}, \mathrm{CS}-\mathrm{A}$ & $(-) 9831,4933$ \\
\hline 59325870 & 2130 & 49 & 1 & 59324407 & CS-A & 3312 \\
\hline 59327098 & 351 & 10 & 1 & 59326903 & CS-A & 816 \\
\hline 59332541 & 359 & 10 & 1 & 59332444 & CS-A, CS-L & $(-) 4725,9906$ \\
\hline 59337566 & 286 & 8 & 1 & 59337553 & CS-A, CS-L & $(-) 9834,4797$ \\
\hline 59339222 & 1045 & 18 & 2 & 59338818 & CS-L, GH & 3532,11112 \\
\hline 59340594 & 831 & 18 & 2 & 59340423 & CS-L, GH & 1927,9507 \\
\hline
\end{tabular}

likely modify $\mathrm{C} / \mathrm{EBP}$ interactions with the basal transcription machinery. This is supported by the fact that the activity of the CSp.CAT.CS-Benh construct is increased by $\mathrm{C} / \mathrm{EBPs}$ suggesting that they exert a direct enhancing effect on the combined promoter-enhancer function.

Additional interactions of the AF- 1 and TEF elements with other sequences in the $C S$ enhancers are likely required for the orchestration of TEF-C/EBP cooperation as suggested by the repression of the enhancer function of the TEF element by both AF-1A and AF-1B (Fig. 2). Thus, although these studies confirm that AF-1 interferes with the interactions of the TEF element with the promoter region, they also suggest that an AF-1/TEF interaction is still not sufficient for enhancer function. However, considering the competition of AF-1 complexes, which are associated, directly or indirectly, with $\mathrm{C} / \mathrm{EBP}$ factors, by TEF oligonucleotides (Fig. 4), our results link the TEF with the $\mathrm{C} / \mathrm{EBP}$ family of factors known to interact with chromatin components and to be involved in transcription factor coactivator recruitment (Mink et al. 1997, Kowenz-Leutz \& Leutz 1999).

The identification of an Ets binding site in the CS-A enhancer (AF-1A) might be significant given that Etssignaling has already been shown (through an Ets-2 null mutation) to be crucial for placental development in mice (Yamamoto et al. 1998). Ets factors appear to play an important role in the development of organs that require extensive tissue remodeling, which includes the placenta, a role that is possibly associated with their effects on the expression of tissue matrix metalloproteinases (Westermarck \& Kahari 1999).

Enhancer sequences have been linked with efficient in vivo expression through interactions with locus control region (LCR) sequences (Anagnou et al. 1995, Stamatoyannopoulos et al. 1997, Jin et al. 1999, 2004).
During placental development the $C S-A$ to $C S-B$ mRNA ratio increases, and this pattern is preserved when the human $\mathrm{GH} / \mathrm{CS}$ locus, including $C S-A$ and $C S-B$, is introduced into transgenic mice (Jin et al. 2009). This suggests that the $C S-A$ gene is more transcriptionally active than its $C S-B$ counterpart at term compared with early placentas. Assuming the functional significance of the $C S-B$ and/or the $C S-A$ enhancer region for efficient expression of the $C S$ genes in vivo, possible explanations for this phenomenon are a) that the $C S-B$ enhancer is the only efficient enhancer in the human GH locus and a switch in promoter selection occurs during the course of placental development in a manner similar to the example of the globin locus (Foley et al. 1994, Langdon \& Kaufman 1998) and b) that the $C S$-A enhancer is in fact active in vivo in spite of the low $C S-A$ enhancer activity in choriocarcinoma cell lines. In partial support of the latter is the fact that stronger $C S-A$ enhancing activity has been observed in primary trophoblast cultures from term placentas (Jacquemin et al. 1996) suggesting that the CS-A enhancer may be more active in mature syncytiotrophoblasts. In addition, the $C S$-A enhancer region has been reported to be hypersensitive specifically in placental cells (Jimenez et al. 1993). Furthermore, specific expression of CS was observed in the placental labyrinth of transgenic mice containing the human $\mathrm{GH}$ LCR and CS-A but lacking the CS-B gene (Jones et al. $1995)$ and, as indicated, the $C S-A$ promoter appears to be more active than the $C S-B$ promoter, based on relative RNA levels, when both genes and enhancer regions are contained in the transgene (Jin et al. 2009). Thus, crosstalk of enhancer (and related factors) with other regulatory sequences in vivo might result in $C S-A$ enhancer function greater than that of the $C S-B$ enhancer. 
We have now identified two candidate members of the Ets and the $\mathrm{C} / \mathrm{EBP}$ families of transcription factors, Elk-1 and $\mathrm{C} / \mathrm{EBP} \alpha / \beta$, which can participate in a functional interplay and affect the $C S-A$ and $C S-B$ enhancers differently. The presence of overlapping Ets and $\mathrm{C} / \mathrm{EBP}$ sites in AF-1A, suggests that a state of equilibrium may normally exist between these factors and the AF-1A but not AF-1B element. This notion is also reflected in the reduction in intensity of the $\mathrm{C} / \mathrm{EBP}-$ related complex on AF-1A, when Elk-1 is overexpressed (Fig. 6B). Furthermore, our array analysis of chromosome 17 sequences in human placental chromatin provides evidence for the existence of a differential $\mathrm{C} / \mathrm{EBP}$ equilibrium on the $\mathrm{AF}-1 \mathrm{~A}$ versus $\mathrm{AF}-1 \mathrm{~B}$ regions. $\mathrm{C} / \mathrm{EBP} \beta$ is the primary $\mathrm{C} / \mathrm{EBP}$ species in the placenta and specifically the villous syncytiotrophoblasts versus cytotrophoblasts (Bamberger et al. 2004), and was, thus, targeted for assessment. C/EBP $\beta$ 'intervals', indicating transcription factor binding in situ, were detected in both the $C S-A$ and $C S-B$ genes. These intervals appear to originate at the $C S-A$ and $C S-B$ enhancer regions and extend out to $\sim 3312$ and 3311 nts downstream of their transcription initiation sites respectively. Importantly, the observed difference in the spread of the C/EBP $\beta$ intervals between the $C S-A$ and $C S-B$ enhancer regions is consistent with a differential impact on $C S-A$ versus $C S-B$ expression. The spread of the $\mathrm{C} / \mathrm{EBP} \beta$ interval over the full $241 \mathrm{bp}$ CS-Benh region including the main TEF-1 site (nts 117-119) may conceivably interfere with effective binding of TEF-1/5 on this enhancer in term placenta. In contrast, in the case of the CS-Aenh, the C/EBP $\beta$ interval starts at the core of the enhancer modulatory domain just upstream of the overlapping Elk-1/C/EBP binding site and expands upstream in the opposite direction relative to the main TEF-1 site, which lies downstream of the modulatory domain (Fig. 11 and Table 1).

The identification of Ets and C/EBP binding sites in the $C S$ enhancer regions raises several possibilities for further investigations. Ets and $\mathrm{C} / \mathrm{EBP}$ proteins are expressed in placenta and have been shown to interact in a variety of tissues and gene contexts, including placental and pituitary gene regulation (Antonson \& Xanthopoulos 1995, Hanlon et al. 2000, Jacob \& Stanley 2001, Bamberger et al. 2004, Lin et al. 2005, Chakrabarty \& Roberts 2007, Hung et al. 2010). We have shown that a site in the $C S-A$ enhancer region can bind at least one member (Elk-1) of the Ets family. Thus, it is possible that this site is a target for additional family members that bind with higher or lower affinity, tissue specificity and a differential ability to interact with $\mathrm{C} / \mathrm{EBP}$ or other regulatory $\mathrm{GH} / \mathrm{CS}$ sequences. Histone modifications within the GH/CS locus have been 'mapped', and the $C S$ enhancer regions are contained in hyperacetylated and hypermethylated domains in placental cells (Kimura et al. 2007). In addition Elk-1 overexpression was reported to induce endogenous $G H / C S$ expression in heterologous human (non-pituitary and nonplacental) cells (Yang et al. 2010). Furthermore, earlier work has implicated the CS enhancers in the pituitary repression of the CS genes (Jiang \& Eberhardt 1997). In combination, these observations raise the possibility that members of the Ets family, possibly in association with $\mathrm{C} / \mathrm{EBPs}$, contribute to the lack of $\mathrm{CS}$ expression in the pituitary by participating in promoter/enhancer complexes and/or promoting chromatin modifications. The latter includes the potential involvement of chromatin loops; the generation of two loops required for specificity and efficient expression during activation of the pituitary GH gene has been described (Ho et al. 2008). In this context, preferential commitment of the $C S-A, C S-B$, or $G H-V$ promoter in a placental cell might be dependent on the relative dynamics of additional regulatory sequences. Further study will be required to address the importance of the relative binding efficiency of $\mathrm{C} / \mathrm{EBP} \alpha$ versus $\mathrm{C} / \mathrm{EBP} \beta$, and the possible role of Elk-1 for tissue specificity and efficient placenta expression. Determining whether the $C S-A$ and $C S-B$ enhancers 'compete' for association with the LCR and/or other regulatory sequences, including additional Ets and $\mathrm{C} / \mathrm{EBP}$ binding sites in the GH/CS locus, will also require further examination.

In summary, C/EBP and Ets binding sites have been identified in the AF-1 regions that differ between the $C S-A$ and $C S-B$ enhancer regions, and have been shown to account, at least in part, for the substantial difference in the activity of the two enhancers in vitro. Our observations are consistent with the participation of factors other than TEF to differentially modulate $C S-A$ and $C S-B$ enhancer activity, presumably either by competing with TEFs for binding or by directly or indirectly interacting with TEFs.

\section{Declaration of interest}

The authors declare that there is no conflict of interest that could be perceived as prejudicing the impartiality of the research reported.

\section{Funding}

This work was supported by a grant from the Canadian Institutes of Health Research (MT-10853).

\section{References}

Anagnou NP, Perez-Stable C, Gelinas R, Costantini F, Liapaki K, Constantopoulou M, Kosteas T, Moschonas NK \& Stamatoyannopoulos G 1995 Sequences located $3^{\prime}$ to the breakpoint of the hereditary persistence of fetal hemoglobin- 3 deletion exhibit enhancer activity and can modify the developmental 
expression of the human fetal A gamma-globin gene in transgenic mice. Journal of Biological Chemistry 270 10256-10263. (doi:10.1074/ jbc.270.17.10256)

Andrews NC \& Faller DV 1991 A rapid micropreparation technique for extraction of DNA-binding proteins from limiting numbers of mammalian cells. Nucleic Acids Research 19 2499. (doi:10.1093/nar/ 19.9.2499)

Antonson P \& Xanthopoulos KG 1995 Molecular cloning, sequence, and expression patterns of the human gene encoding CCAAT/ enhancer binding protein alpha (C/EBP alpha). Biochemical and Biophysical Research Communications 215 106-113. (doi:10.1006/ bbrc.1995.2439)

Bamberger AM, Makrigiannakis A, Schroder M, Bamberger CM, Relakis C, Gellersen B, Milde-Langosch K \& Loning T 2004 Expression pattern of the CCAAT/enhancer-binding proteins C/EBP-alpha, C/EBP-beta and C/EBP-delta in the human placenta. Virchows Archiv 444 149-152. (doi:10.1007/s00428-0030935-7)

Bradford MM 1976 A rapid and sensitive method for the quantitation of microgram quantities of protein utilizing the principle of protein-dye binding. Analytical Biochemistry 72 248-254. (doi:10. 1016/0003-2697(76)90527-3)

Cattini PA \& Eberhardt NL 1987 Regulated expression of chimaeric genes containing the $5^{\prime}$-flanking regions of human growth hormone-related genes in transiently transfected rat anterior pituitary tumor cells. Nucleic Acids Research 15 1297-1309. (doi:10. 1093/nar/15.3.1297)

Chakrabarty A \& Roberts MR 2007 Ets-2 and C/EBP-beta are important mediators of ovine trophoblast Kunitz domain protein-1 gene expression in trophoblast. BMC Molecular Biology 8 14. (doi:10. 1186/1471-2199-8-14)

Foley KP, Pruzina S, Winick JD, Engel JD, Grosveld F \& Fraser P 1994 The chicken beta/epsilon-globin enhancer directs autonomously regulated, high-level expression of the chicken epsilon-globin gene in transgenic mice. PNAS 91 7252-7256. (doi:10.1073/pnas.91.15. 7252)

Hanlon M, Bundy LM \& Sealy L 2000 C/EBP beta and Elk-1 synergistically transactivate the c-fos serum response element. $B M C$ Cell Biology 1 2. (doi:10.1186/1471-2121-1-2)

Ho Y, Tadevosyan A, Liebhaber SA \& Cooke NE 2008 The juxtaposition of a promoter with a locus control region transcriptional domain activates gene expression. EMBO Reports 9 891-898. (doi:10.1038/embor.2008.126)

Hung CC, Liu X, Kwon MY, Kang YH, Chung SW \& Perrella MA 2010 Regulation of heme oxygenase-1 gene by peptidoglycan involves the interaction of Elk-1 and C/EBPalpha to increase expression. American Journal of Physiology. Lung Cellular and Molecular Physiology 298 L870-L879. (doi:10.1152/ajplung.00382.2009)

Jacob KK \& Stanley FM 2001 Elk-1, C/EBPalpha, and Pit-1 confer an insulin-responsive phenotype on prolactin promoter expression in Chinese hamster ovary cells and define the factors required for insulin-increased transcription. Journal of Biological Chemistry 276 24931-24936. (doi:10.1074/jbc.M102826200)

Jacquemin P, Oury C, Peers B, Morin A, Belayew A \& Martial JA 1994 Characterization of a single strong tissue-specific enhancer downstream from the three human genes encoding placental lactogen. Molecular and Cellular Biology 14 93-103.

Jacquemin P, Alsat E, Oury C, Belayew A, Muller M, Evain-Brion D \& Martial JA 1996 The enhancers of the human placental lactogen B, $\mathrm{A}$, and L genes: progressive activation during in vitro trophoblast differentiation and importance of the DF-3 element in determining their respective activities. DNA and Cell Biology 15 845-854. (doi:10. 1089/dna.1996.15.845)

Jacquemin P, Martial JA \& Davidson I 1997 Human TEF-5 is preferentially expressed in placenta and binds to multiple functional elements of the human chorionic somatomammotropinB gene enhancer. Journal of Biological Chemistry 272 12928-12937. (doi:10.1074/jbc.272.20.12928)
Jiang SW \& Eberhardt NL 1994 The human chorionic somatomammotropin gene enhancer is composed of multiple DNA elements that are homologous to several SV40 enhansons. Journal of Biological Chemistry 269 10384-10392.

Jiang SW \& Eberhardt NL 1995 Involvement of a protein distinct from transcription enhancer factor-1 (TEF-1) in mediating human chorionic somatomammotropin gene enhancer function through the GT-IIC enhanson in choriocarcinoma and COS cells. Journal of Biological Chemistry 270 13906-13915. (doi:10.1074/jbc.270.23. 13906)

Jiang SW \& Eberhardt NL 1996 TEF-1 transrepression in BeWo cells is mediated through interactions with the TATA-binding protein, TBP. Journal of Biological Chemistry 271 9510-9518. (doi:10.1074/jbc. 271.16.9510)

Jiang SW \& Eberhardt NL 1997 The human chorionic somatomammotropin enhancers form a composite silencer in pituitary cells in vitro. Molecular Endocrinology 11 1233-1244. (doi:10.1210/me.11. 9.1233)

Jiang SW, Trujillo MA \& Eberhardt NL 1997 Human chorionic somatomammotropin enhancer function is mediated by cooperative binding of TEF-1 and CSEF-1 to multiple, low-affinity binding sites. Molecular Endocrinology 11 1223-1232. (doi:10.1210/me.11.9.1223)

Jiang SW, Wu K \& Eberhardt NL 1999 Human placental TEF-5 transactivates the human chorionic somatomammotropin gene enhancer. Molecular Endocrinology 13 879-889. (doi:10.1210/me.13. 6.879)

Jiang SW, Desai D, Khan S \& Eberhardt NL 2000 Cooperative binding of TEF-1 to repeated GGAATG-related consensus elements with restricted spatial separation and orientation. DNA and Cell Biology 19 507-514. (doi:10.1089/10445490050128430)

Jimenez G, Ford AM, Enver T \& Boronat A 1993 Multiple changes in chromatin structure precede the transcriptional activation of the human growth hormone locus in placental cells. Molecular and Cellular Endocrinology 96 53-60. (doi:10.1016/0303-7207(93) 90094-Z)

Jin Y, Surabhi RM, Fresnoza A, Lytras A \& Cattini PA 1999 A role for A/T-rich sequences and Pit-1/GHF-1 in a distal enhancer located in the human growth hormone locus control region with preferential pituitary activity in culture and transgenic mice. Molecular Endocrinology 13 1249-1266. (doi:10.1210/me.13.8.1249)

Jin Y, Norquay LD, Yang X, Gregoire S \& Cattini PA 2004 Binding of AP-2 and ETS-domain family members is associated with enhancer activity in the hypersensitive site III region of the human growth hormone/chorionic somatomammotropin locus. Molecular Endocrinology 18 574-587. (doi:10.1210/me.2003-0405)

Jin Y, Lu SY, Fresnoza A, Detillieux KA, Duckworth ML \& Cattini PA 2009 Differential placental hormone gene expression during pregnancy in a transgenic mouse containing the human growth hormone/chorionic somatomammotropin locus. Placenta $\mathbf{3 0}$ 226-235. (doi:10.1016/j.placenta.2008.12.011)

Jones BK, Monks BR, Liebhaber SA \& Cooke NE 1995 The human growth hormone gene is regulated by a multicomponent locus control region. Molecular and Cellular Biology 15 7010-7021.

Kimura AP, Sizova D, Handwerger S, Cooke NE \& Liebhaber SA 2007 Epigenetic activation of the human growth hormone gene cluster during placental cytotrophoblast differentiation. Molecular and Cellular Biology 27 6555-6568. (doi:10.1128/MCB. 00273-07)

Kowenz-Leutz E \& Leutz A 1999 A C/EBP beta isoform recruits the SWI/SNF complex to activate myeloid genes. Molecular Cell 4 735-743. (doi:10.1016/S1097-2765(00) 80384-6)

Langdon SD \& Kaufman RE 1998 Gamma-globin gene promoter elements required for interaction with globin enhancers. Blood 91 309-318.

Lin L, Stringfield TM, Shi X \& Chen Y 2005 Arsenite induces a cell stress-response gene, RTP801, through reactive oxygen species and transcription factors Elk-1 and CCAAT/enhancer-binding protein. Biochemical Journal 392 93-102. (doi:10.1042/BJ20050553) 
Lytras A \& Cattini PA 1994 Human chorionic somatomammotropin gene enhancer activity is dependent on the blockade of a repressor mechanism. Molecular Endocrinology 8 478-489. (doi:10.1210/me.8. 4.478)

Lytras A, Surabhi RM, Zhang JF, Jin Y \& Cattini PA 1996 "Repair" of the chorionic somatomammotropin-A "enhancer" region reveals a novel functional element in the chorionic somatomammotropin-B enhancer. Molecular and Cellular Endocrinology 119 1-10. (doi:10. 1016/0303-7207(96)03777-X)

Mink S, Haenig B \& Klempnauer KH 1997 Interaction and functional collaboration of p300 and C/EBPbeta. Molecular and Cellular Biology 17 6609-6617.

Nachtigal MW, Nickel BE \& Cattini PA 1993 Pituitary-specific repression of placental members of the human growth hormone gene family. A possible mechanism for locus regulation. Journal of Biological Chemistry 268 8473-8479.

Nickel BE, Kardami E \& Cattini PA 1990 Differential expression of human placental growth-hormone variant and chorionic somatomammotropin in culture. Biochemical Journal 267 653-658.

Rogers BL, Sobnosky MG \& Saunders GF 1986 Transcriptional enhancer within the human placental lactogen and growth hormone multigene cluster. Nucleic Acids Research 14 7647-7659. (doi:10.1093/nar/14.19.7647)

Stamatoyannopoulos JA, Clegg CH \& Li Q 1997 Sheltering of gammaglobin expression from position effects requires both an upstream locus control region and a regulatory element $3^{\prime}$ to the A gammaglobin gene. Molecular and Cellular Biology 17 240-247.
Stephanou A \& Handwerger S 1995 The nuclear factor NF-IL6 activates human placental lactogen gene expression. Biochemical and Biophysical Research Communications 206 215-222. (doi:10.1006/ bbrc.1995.1030)

Walker WH, Fitzpatrick SL \& Saunders GF 1990 Human placental lactogen transcriptional enhancer. Tissue specificity and binding with specific proteins. Journal of Biological Chemistry $\mathbf{2 6 5}$ 12940-12948.

Westermarck J \& Kahari VM 1999 Regulation of matrix metalloproteinase expression in tumor invasion. FASEB Journal 13 781-792.

Xiao JH, Davidson I, Matthes H, Garnier JM \& Chambon P 1991 Cloning, expression, and transcriptional properties of the human enhancer factor TEF-1. Cell 65 551-568. (doi:10.1016/00928674(91)90088-G)

Yamamoto H, Flannery ML, Kupriyanov S, Pearce J, McKercher SR, Henkel GW, Maki RA, Werb Z \& Oshima RG 1998 Defective trophoblast function in mice with a targeted mutation of Ets2. Genes and Development 12 1315-1326. (doi:10.1101/gad.12.9.1315)

Yang X, Jin Y \& Cattini PA 2010 Appearance of the pituitary factor Pit-1 increases chromatin remodeling at hypersensitive site III in the human GH locus. Journal of Molecular Endocrinology 45 19-32. (doi:10.1677/JME-10-0017)

Received in final form 8 June 2011

Accepted 7 July 2011

Made available online as an Accepted Preprint 7 July 2011 